Gut, 1971, 12, 468-482

\title{
Polyps of the rectum and colon
}

\author{
F. POTET AND J. SOULLARD
}

From the Department of Morbid Anatomy, Hôpital Beaujon, Clichy, and Hôpital Bichat, Paris

SUMMARY Four hundred and thirty-three patients with adenomatous polyps were examined and followed up. It was found that well differentiated adenomas are stable but dedifferentiated polyps can lead to invasive cancer, usually over a long period of time. Thus the concept of malignant transformation becomes meaningless, and should be replaced by an initial histological evaluation of polyps of the rectum and colon so that their development can be predicted.

The large number of papers published in recent years about polyps of the colon and rectum have failed to solve the problems concerning their incidence in adults, their situation in the colon and rectum, the criteria for distinguishing benign and malignant polyps, and their relationship to carcinoma.

\section{Incidence}

Contradictory statistics for the incidence of polyps have been reported. Chapman (1963) states that $51 \%$ of adults are affected, and that the incidence increases with advancing years up to $88 \%$ in centenarians. Bargen (1963), examining colons at necropsy under a magnifying glass, found an incidence of $69 \%$. Arminski and McLean (1964) give a mean incidence of $41.3 \%$, with a $7.5 \%$ increase every decade. On the other hand Ekelund (1963) found an incidence of only $12.5 \%$ in 3,398 necropsies and Martin and Sutton (1965) a mean of $10 \%$ only, ranging from 2.8 to $21.5 \%$. This is an important problem because if the incidence of polyps were as high as the first group of authors claim it to be, no relationship to cancer could be upheld. Thus Ackermann, Spjut, and Spratt (1964), considering the incidence of polyps and cancer in one million persons, give a mean ratio of 133 polyps for one cancer and a maximum ratio of 538 polyps to one cancer.

\section{Distribution}

The distribution of polyps in the colon is also debated. The general view is that two-thirds of the neoplasms (polyps or cancers) arise in the rectum and sigmoid colon. Mayo and Pagtaleman (1963) have found that $70 \%$ occur in the rectum or Received for publication 23 March 1971. sigmoid colon, and Martin and Sutton (1965) found 70 to $80 \%$. In the opinion of Ekelund (1963) $56 \%$ of solitary polyps arise in the rectum and sigmoid colon, while only $33 \%$ of multiple polyps arise there. Welch, McKittrick, and Behringer (1952) found $73 \%$ of polyps in the last $25 \mathrm{~cm}$ of the colon but Chapman (1963) found that most polyps arose in the proximal colon (77\%). Feyrter (1931) and Arminski and McLean (1964) agreed with the latter opinion, their rates being respectively 75 and $70 \%$. If this were true, it would be illusory to try to detect polyps by proctoscopic examination, or even cancers arising in polyps. Other authors go further and deny any correlation between polyps and cancer after comparing their respective sites. Thus Ackermann et al (1964), comparing the sites of 100 cancers and 100 polyps, found half as many polyps as cancers in the rectum. However, most authorities, like Fitts (1961), find a topographical correlation between polyps and cancers. With his own data at two different periods, Fitt shows how much these statistics can vary, depending on the more or less regular use of proctoscopy and radiological examination.

\section{Relationship of Polyps to Cancer}

This is the most important problem, and approaches to it vary. The first difficulty is terminology. Different authors use different terms, which are sometimes contradictory or meaningless. The most remarkable of these misunderstandings can be found in the statistics of the Massachusets General Hospital (Welch et al, 1952) which have been reviewed by Castelman and Krickstein (1962) who studied the same material and reached completely different conclusions.

A relationship between polyps and cancer is 
acknowledged by all authors, except Spratt and Ackermann (1961). For example, in one study (Rider, Kirsner, Moeller, and Palmer, 1959) of 9,132 patients $2 \cdot 1 \%$ showed cancer without any polyps, $11.6 \%$ with one polyp only, and $20.7 \%$ in those with multiple polyps. Moreover, these percentages decrease dramatically to $3.2 \%$ in patients observed from the fourth to the ninth year after ablation of the polyps. Hellwig (1960), Enterline, Evans, Mercudo, Miller, and Fitts (1962), Knight, (1963), Grinnel (1964), and Lesher, Dockerty, Jackman, and Beahrs (1967) give similar results. Awareness of the relationship between polyps and cancer has given rise to the belief that intestinal cancer arises from pre-existing polyps. This suggestion is tempting because few cancers are known to result from previously normal mucosa (Morson, 1966; Helwig, 1960; Grinnel, 1964; Stearns, 1963; Bockus, Tachdjian, Ferguson, Mouhran, and Chamberlain, 1961).

\section{Where Does Malignancy Start?}

Different publications on the subject reveal a great variety of definitions, more or less pejorative-from minor cytological changes to architectural abnormalities and to macroscopic aspects of pedunculated cancer at the stage where they are capable of metastasizing and spreading to lymph nodes. Most authors confine themselves to decisions about benignancy or malignancy without considering the pathogenesis. This explains the frequency of contradictory statements among pathologists. If polyps are prone to become malignant, the genesis of this malignancy is obscure. Where and when does it appear? It is strange that a glandular proliferation, with morphological and physiological characteristics closely resembling those of normal intestinal glands, should become an anarchic combination of cells that have lost all similarity to their histological model and all trace of secretory function. Despite analogies in other areas of pathology, this change is highly questionable.

\section{The Present Study}

The object of the present study was to contribute towards a solution for these unsolved problems. We have tried in particular to give an answer to the following questions. Is it possible to define, histologically, a minimal malignancy and to anticipate, and therefore to prevent, the appearance of unquestionably malignant change? To what extent, by using such a definition, can a sure distinction be drawn between benign and malignant evolution? Will the appraisal of this limited objective be based 4 on qualitative tests, that is, on the presence or absence of certain features, or on quantitative factors submitted to a subjective evaluation? This reservation being made, does the evolution of socalled benign polyps justify the histologist's optimism? Does the malignant polyp follow a downhill course, as the histologist implies, and can the stages of transformation into carcinoma be described? Finally, what will become of the idea of malignant transformation if the benign polyp stays benign and if the malignant polyp seems to behave malignantly from its inception.

\section{Material and Methods}

Our material includes 530 patients with polyps (excluding villous papillomas) defined by Morson's criteria (1962) in which the word 'polyp' is only used for a small tumour which is clinically visible and raised above the intestinal mucous membrane. The 530 patients were all examined clinically and the polyps were all studied by the same pathologist. When subjects under 20 years old, who only had juvenile polyps, are eliminated, 485 patients remain, of whom $52(10.7 \%)$ had non-adenomatous polyps (Table I). Juvenile polyps have a higher incidence

\begin{tabular}{lll}
\hline Type of Polyp & No. & Percentage of 485 Patients \\
\hline Simple glandular hyperplasia & 7 & $1 \cdot 5$ \\
Lymphoma & 7 & $1 \cdot 5$ \\
Carcinoid tumour & 6 & $1 \cdot 2$ \\
Myoma & 1 & $0 \cdot 2$ \\
Lipoma & 1 & $0 \cdot 2$ \\
Lymphangioma & 1 & $0 \cdot 2$ \\
Juvenile polyp & 29 & $5 \cdot 9$ \\
\hline
\end{tabular}

Table I Distribution of non-adenomatous polyps in 52 patients

than others in this group. These belong to two types: some are pseudopolyps of Wechselmann (1910), others resemble juvenile polyps. This leaves for study $433(89.3 \%)$ patients with polyps discovered on proctoscopic examination, the initial assumption being that all were adenomas. Punch cards were made for these 433 patients, indicating the sex, age, the circumstances of discovery of the polyps, the number and size of the polyps, whether they were pedunculated or not, their site and treatment. All patients were followed up, several attending several times, and finally 217 were studied. The incidence of recurrence was examined in this last group only.

\section{Classification}

The histopathological characteristics were studied using a classification in which glandular differentia- 


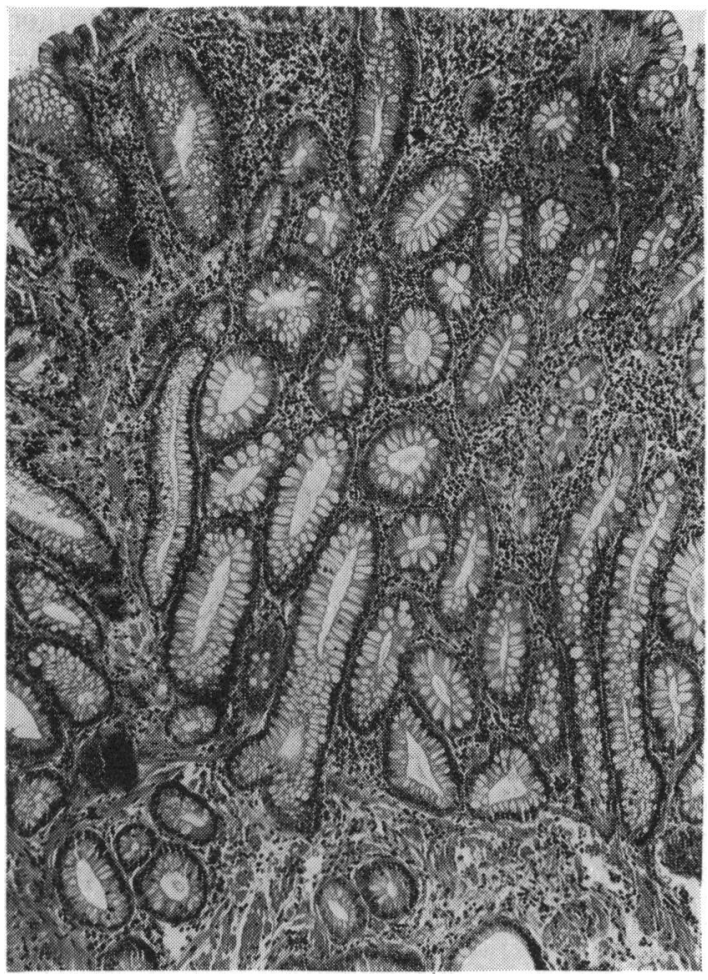

Fig. 1 Well differentiated polyp: note the normal glandular pattern with more than $80 \%$ of goblet cells. $\times 120$ tion, with loss of normal differentiation and cytological changes, were the main criteria.

The normal colonic mucosa contains glandular tubes lined with columnar cells having a striated border made of microvilli. At least $80 \%$ of these cells have a large mucin-filled goblet pouring its contents into the lumen of the tube. They have a long dark stalk containing a vertical nucleus near the base of the cell. All the nuclei are on the same level. The other $20 \%$ are darker cells without any secretion or with just a few droplets of mucin near the apex. The secretion of mucin is demonstrated by using stains for acid mucopolysaccharides, such as alcian blue, mucicarmine, and alcian green. To compare the appearance of adenomatous polyps with carcinoma we have classified them by the degree of dedifferentiation and cytological appearances.

Dedifferentiation can be judged either by a reduction in the goblet cells, localization in the apex rather than in the whole cell, by a decrease in goblet cells in the glands to less than $60 \%$, or by the persistence of only a few droplets of mucin here and there in the apical cytoplasm shown after staining with alcian blue. Therefore, a well differentiated polyp (Fig. 1) will resemble the normal glandular mucosa with more than $80 \%$ of goblet cells, all the glands being the same. These polyps are not just plaques of simple, non-neoplastic hyperplasia, because of the tortuous glandular pattern, the abnormal height of the cells and goblets, and the more abundant lamina propria. The 'hyperplastic' polyps (Fig. 2) of

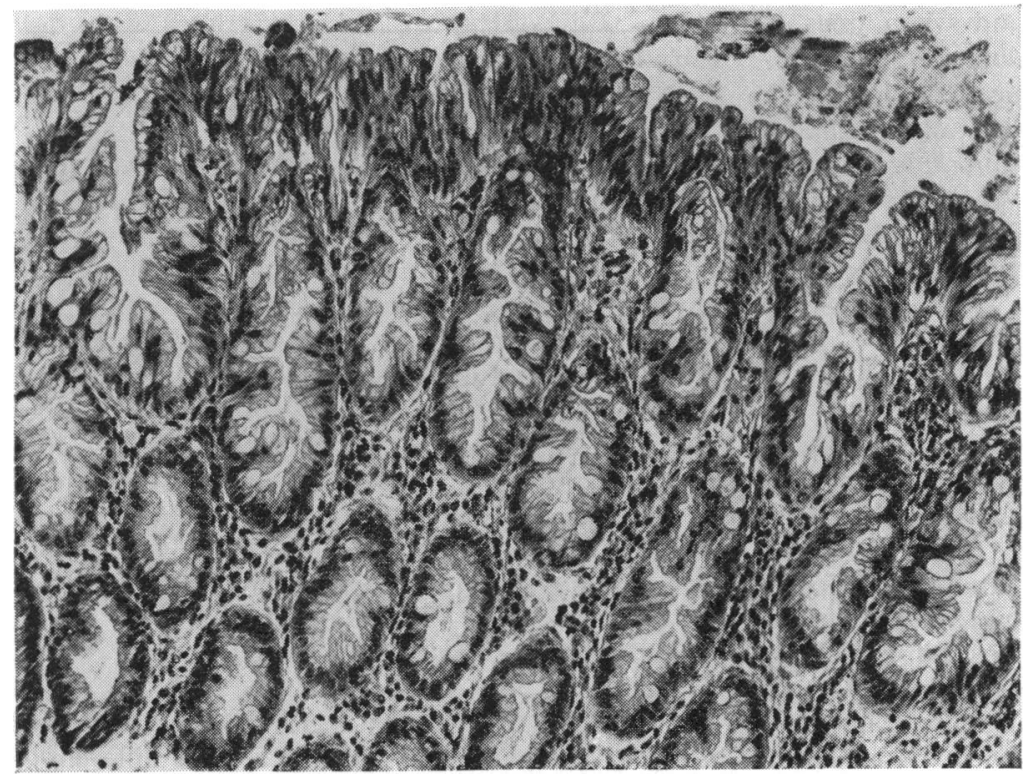

Fig. 2 Hyperplastic polyp (Morson's metaplastic polyp) $\times 225$. 
American authors would belong to this category, called by Morson and Bussey (1970) 'metaplastic'. It does not seem logical to us to separate these formations from bigger and less well differentiated polyps.

The extent of dedifferentiation, as described above, varies: it can reach certain glands or groups of glands, leaving others well differentiated. From this viewpoint three categories have been defined.

(1) Adenomatous polyps, in which less than onethird of the glands are dedifferentiated: here there are only very limited patches of dedifferentiation, mostly near the surface of the tumour. It seems to us that cells, pushed aside by the cellular growth on the surface, could afterwards regain normal differentiation. This would be a sign of tumour activity and in this case the tumour would keep its normal secretory potential.

(2) Adenomatous polyps in which the dedifferentiation extends to between one-third and two-thirds of the proliferous growth, a class of polyps which we found difficult to interpret (Fig. 3).

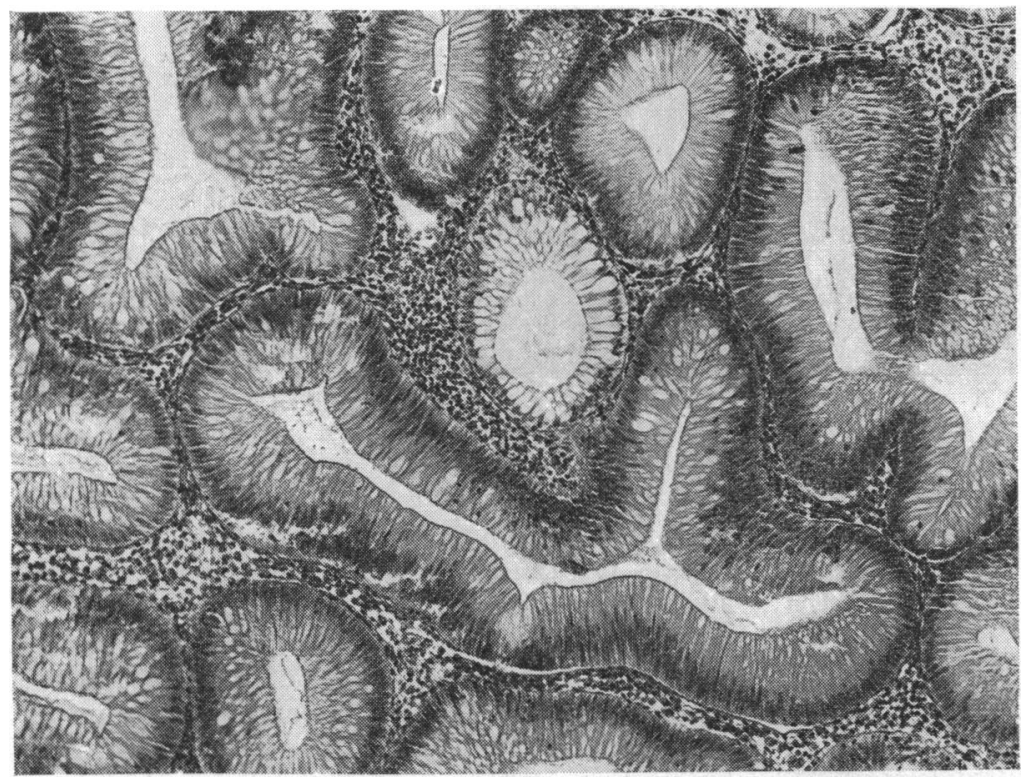

Fig. 3 Dedifferentiated polyp: two-thirds of the proliferating growth is dedifferentiated with partial conservation of goblet cells. $\times 155$.

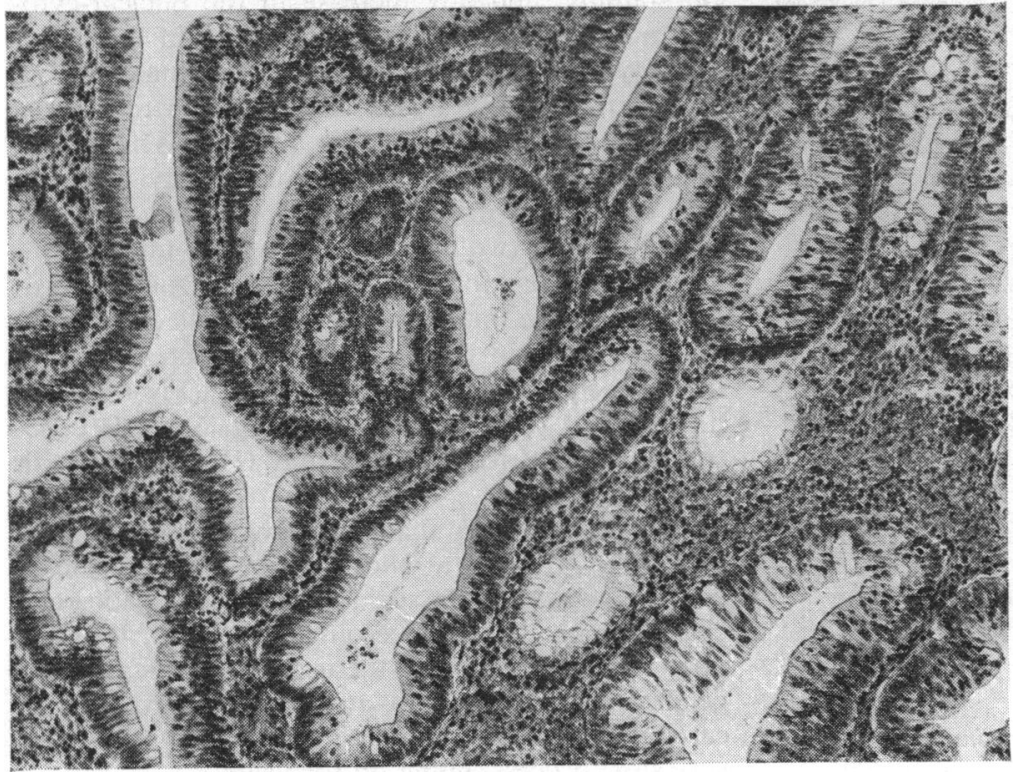

Fig. 4 Completely dedifferentiated polyp. $\times 180$. 


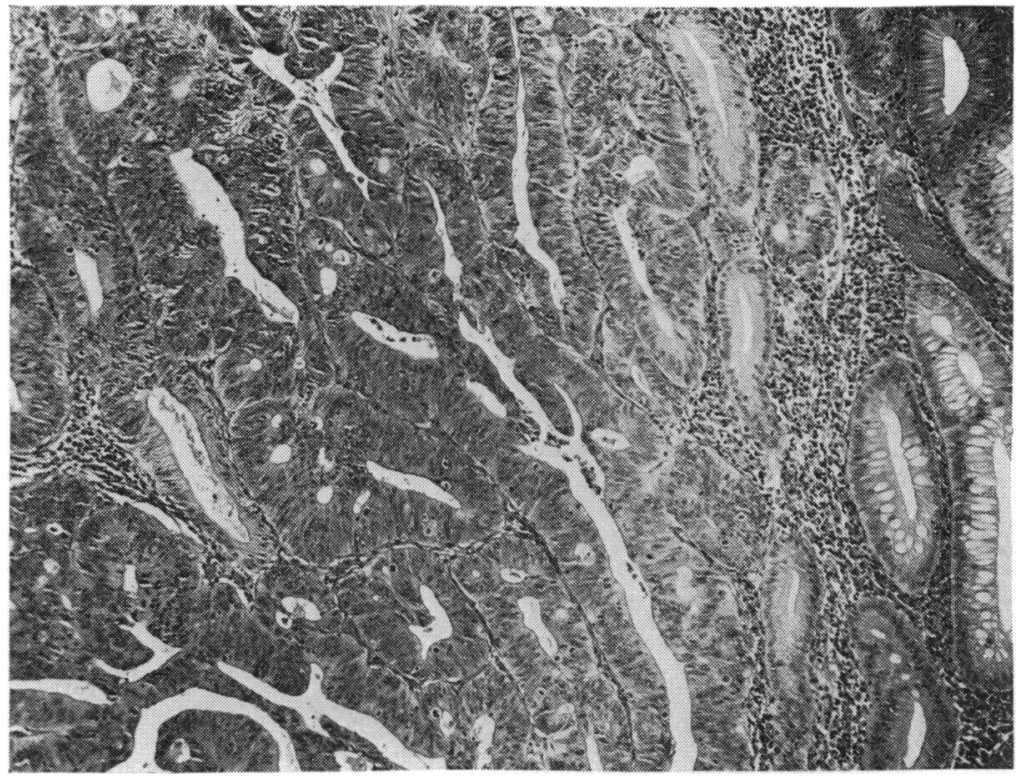

Fig. 5 Malignant polyp (stage I) with involoement of the lamina propria. $\times 125$.

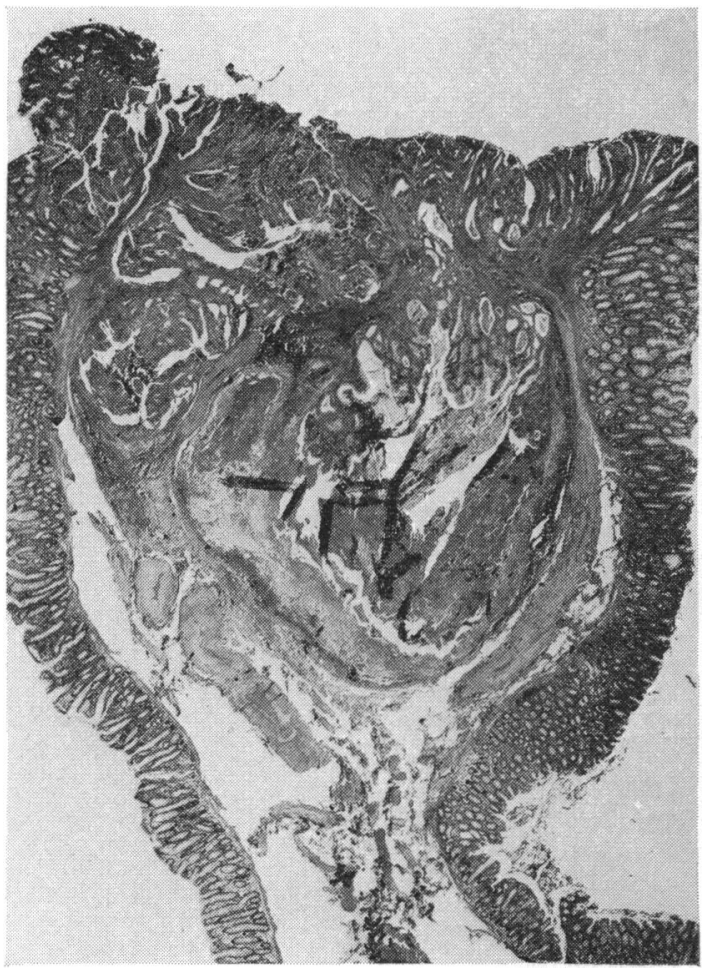

Fig. 6 Malignant polyp (stage II) with involvement of the stalk. $\times 15$.
(3) Adenomatous polyps where dedifferentiation exceeds two-thirds of the neoplasm and sometimes all of it (Fig. 4).

Besides the criteria of dedifferentiation, a classification must take account of the cytological characteristics of the growth, for example, nuclear irregularity, the numbers of mitotic figures, chromatin staining, and any increase in the nuclear-cytoplasmic ratio. Also any inversion of secretory polarity, a more basophil cytoplasm, inequality in the distribution of nuclei, multistratification, or a polyadenoid aspect must be judged. When these cytological characteristics of malignancy exist we are describing malignant polyps which can be separated into two categories. First are unquestionable carcinomas for which we prefer Duke's classification to one that is applicable to all cancers. In this classification there are four distinct stages: (I) involvement of the lamina propria (Fig. 5); (II) involvement of the submucosa (Fig. 6); (III) penetration of the whole wall; and (IV) cancer with metastases.

It is well known that the term, cancer in situ, created by Broden at the Mayo Clinic, involves a possible paradoxical association between a cancerous cytology and a non-cancerous topography. It seems now to be proved that these cancerous states can persist indefinitely or at any moment give rise to carcinoma. Thus the cancer could be the result of a very slow process, going on for years. 


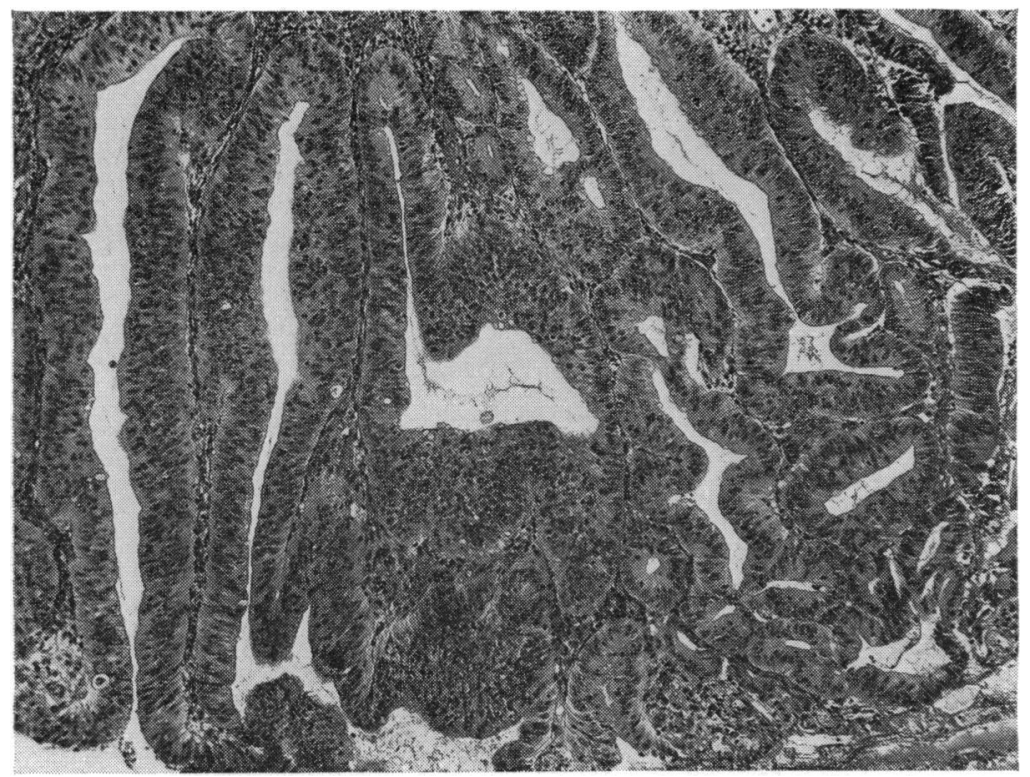

Fig. 7 Cancer 'in situ'. It is often very difficult to draw the line between a complete dedifferentiation (Fig. 4) and a true cytological carcinoma. $\times 120$.

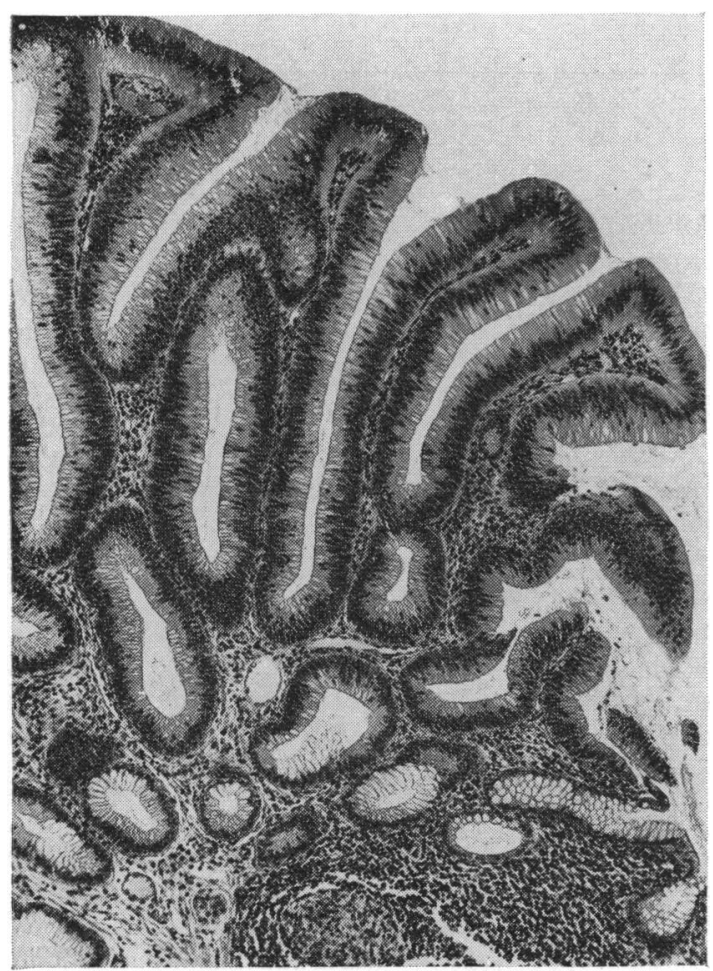

Fig. 8 Villous polyadenoma. Note the double aspectdeeply adenomatous and superficially villous. $\times 135$.
In the case of rectal polyps, cancer in situ can be described as a cytological stage of cancer marked by the loss of secretory function and the presence of cytological and nuclear anomalies. However, in many instances it is difficult to draw the exact line between complete dedifferentiation with just a few anomalies and irregularities and a true cytological cancer in situ (Fig. 7). This is the reason why the same slides can be judged differently by different histologists.

Finally, a last element in classification is worth noting. Some polyps have a double aspect: deeply there is adenomatous proliferation and superficially the appearance is of a villous papilloma, and so we call them 'villous polyadenomas' (Fig. 8).

We can now define six classes of glandular polyps: (1) well differentiated polyps, (2) less than one-third dedifferentiated polyps, (3) completely dedifferentiated polyps, (4) villous polyadenoma (villous papilloma), (5) malignant polyps in situ, and (6) malignant stage I and II polyps.

\section{Results}

SEX AND AGE

Men are affected more often than women, and Fig. 9 shows that adenomatous polyps are not seen in children (except in cases of familial polyposis) and are rare up to 40 years of age. The highest incidence, 


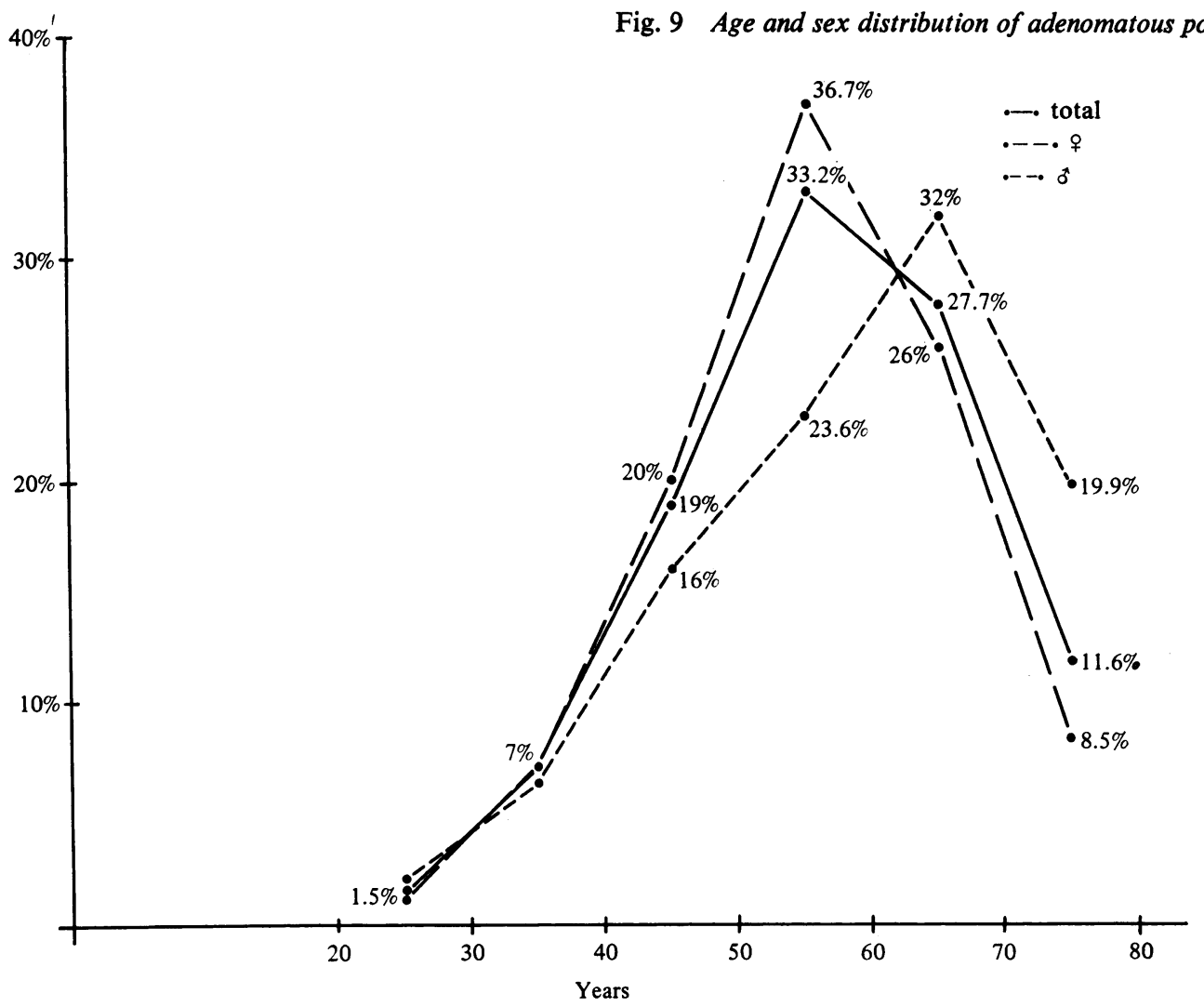

$80 \%$ of all cases, is between 40 and 70 years, the peak being between 50 and 60 years in men. In women the peak is 10 years later. After 70 years of age the number of polyps decreases because of natural mortality. Because of women's greater longevity, $20 \%$ of polyps occur after this age in women.

\section{INCIDENCE AND DISTRIBUTION}

Our small necropsy series of 85 adults of all ages showed that 19 had polyps, 12 occurring in the rectum and sigmoid colon and seven in the rest of the colon. These figures are in accordance with the widespread opinion that polyps are more frequent in the rectum and sigmoid colon and contrary to the very high incidence found by some other authors (Bargen, 1963; Arminski and McLean, 1964).

\section{CLINICAL SYMPTOMS}

Bleeding was the only significant symptom and was found in $64.5 \%$ of cases. But this symptom can be the result of haemorrhoidal bleeding. In fact, in $26 \%$ of cases in which bleeding occurred haemorrhoids were present. So it is possible that these and not the polyps were the cause of bleeding. But $35.5 \%$ of our patients with polyps had no bleeding.

The incidence of bleeding increases when the histological type grows more severe, as shown in Figure 10. Bleeding is also more frequent if the polyp is larger (Fig. 11).

PERCENTAGE OF THE DIFFERENT HISTOLOGICAL TYPES

Figure 12 shows that $53 \%$ of the polyps were judged to be benign and $29 \%$ potentially or actually malignant. Between these two groups $18 \%$ are polyps in which one half or two-thirds of the glands are dedifferentiated, and in which any prognosis would be uncertain, as it was difficult to tell if the evolution would be benign or malignant.

INCIDENCE AND HISTOLOGY ACCORDING TO SIZE

This relationship is difficult because the size of polyps is not easily estimated and is often undervalued on proctoscopic examination. Three-quarters of polyps are less than $10 \mathrm{~mm}$ in diameter. Only one- 


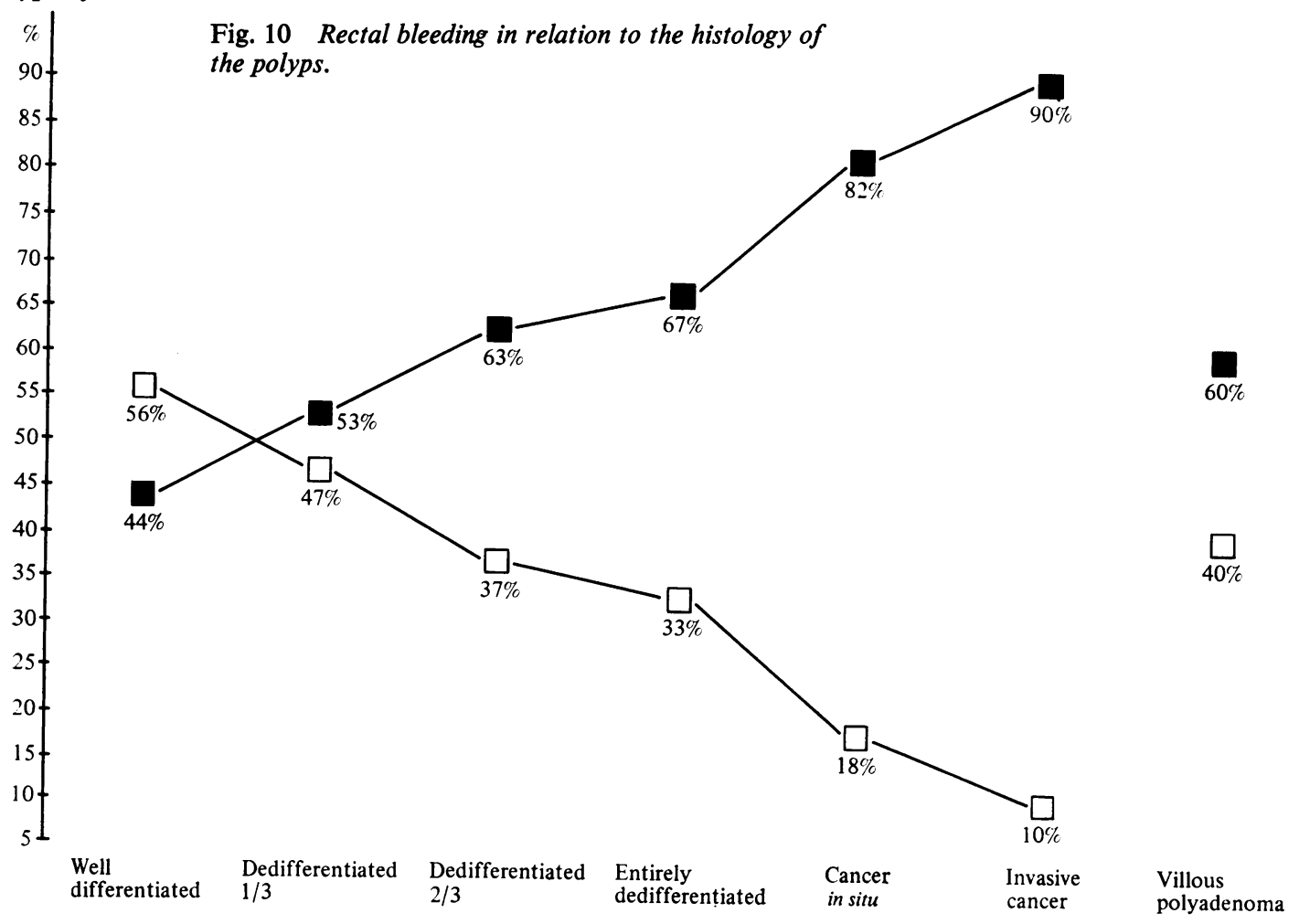

$\%$

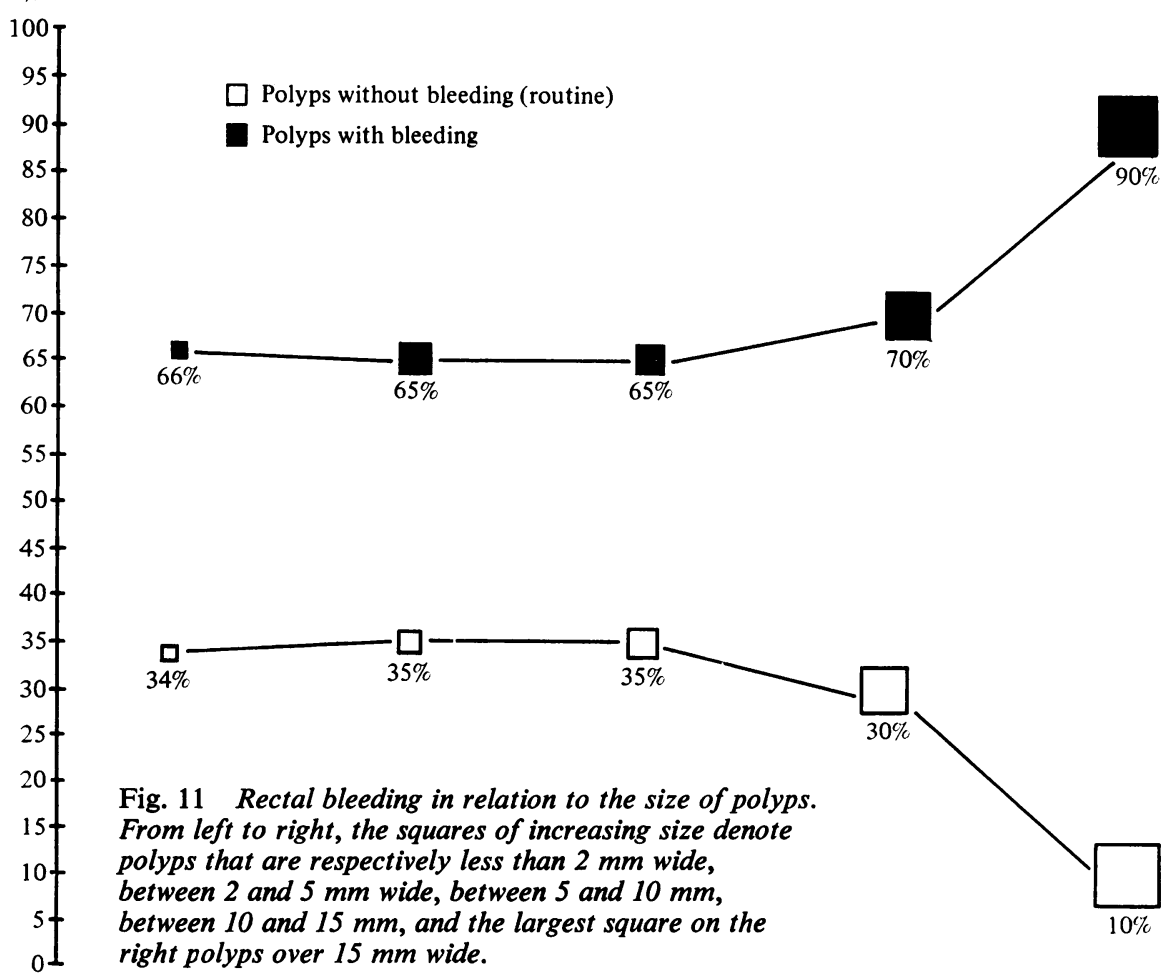




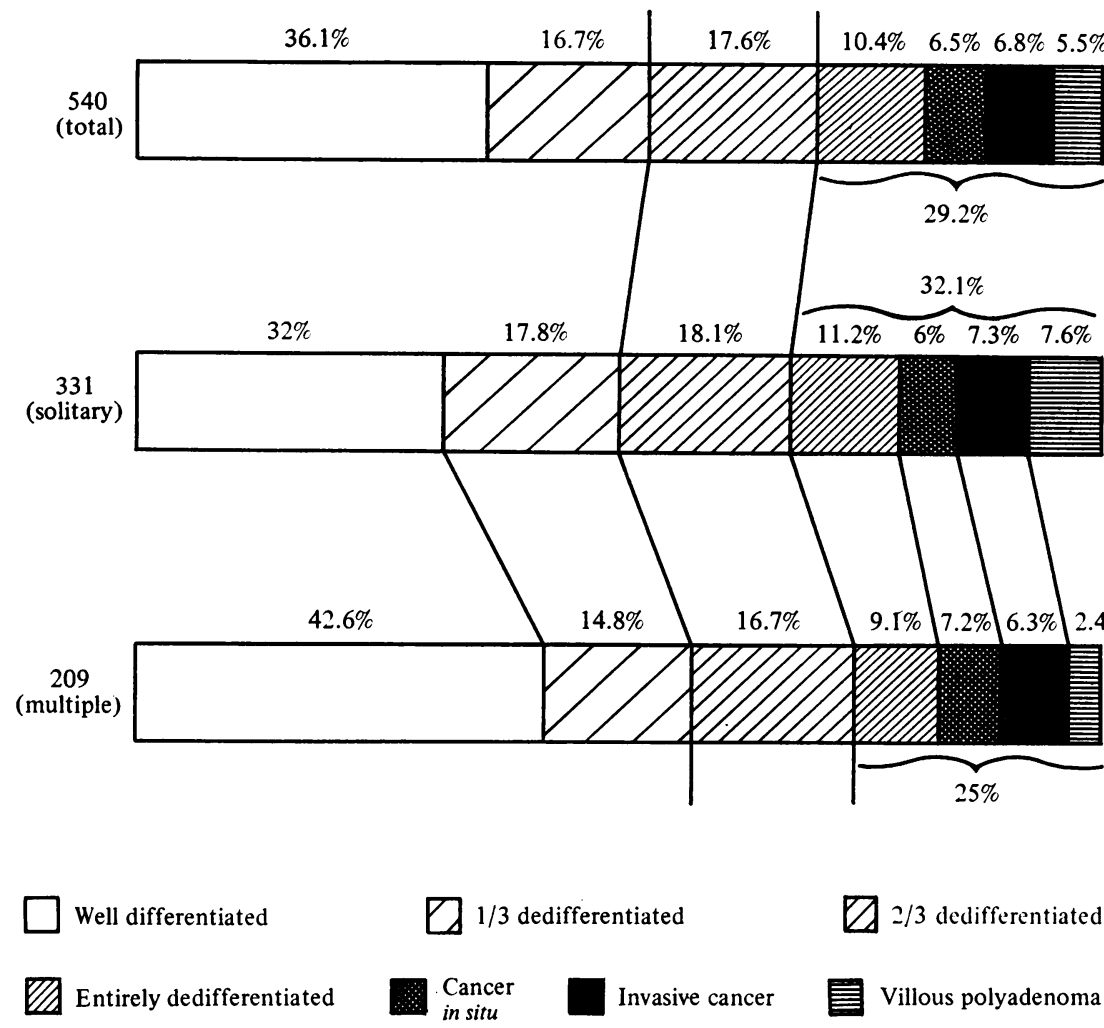

Fig. 12 Distribution of the different histological types of solitary and multiple polyps.

The key applies to both Figures 12 and 13.

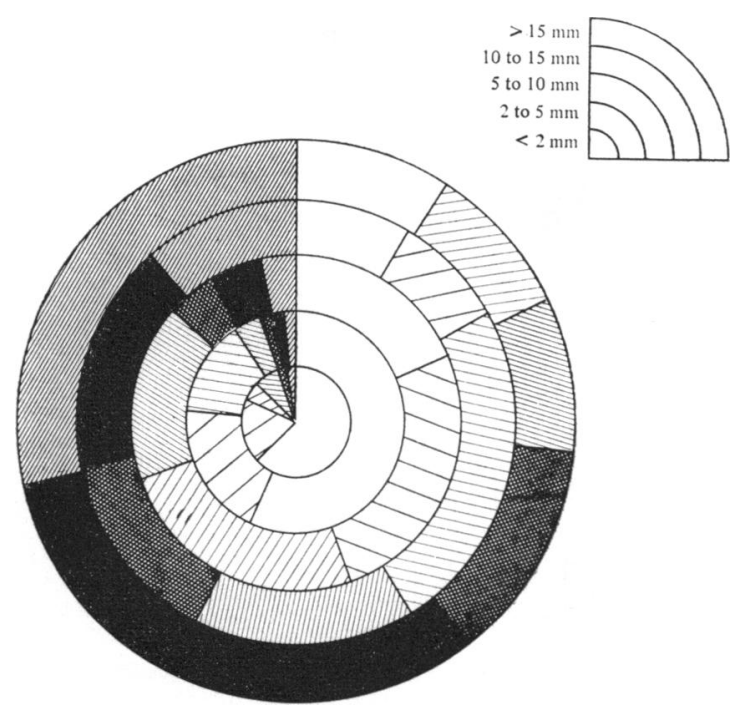

Fig. 13 Histology in relation to the size: the circles of different diameters indicate the size of the polyps and in each circle the proportion of polyps in different histological categories. quarter are larger. Figure 13 shows that the proportion of benign lesions decreases when size increases. Yet it must be remembered that small polyps$13 \%$ of polyps less than $2 \mathrm{~mm}$ and $10 \%$ of those under $5 \mathrm{~mm}$-can be potentially malignant. The gulf between the percentages for the benign and the malignant histological aspects is spanned by the uncertain histology of polyps with two-thirds of their glands dedifferentiated.

HISTOLOGY OF POLYPS WITH A LONG PEDUNCLE We have separated neoplasms with a pedicle at least as long as the tumour is wide. These are usually tumours heavy enough to weigh down and thus elongate the nearby normal mucosa. Contrary to general opinion, we found that $55 \%$ of this type of tumour were potentially or actually malignant. But this is easily explained by the fact that long pedicles are usually found with big polyps.

\section{HISTOLOGICAL TYPES AT DIFFERENT AGES}

The proportion of various histological types is about the same in the different decades of life (Fig. 14). Negligible until 40 years, the proportions of benign and malignant polyps change very little between 40 


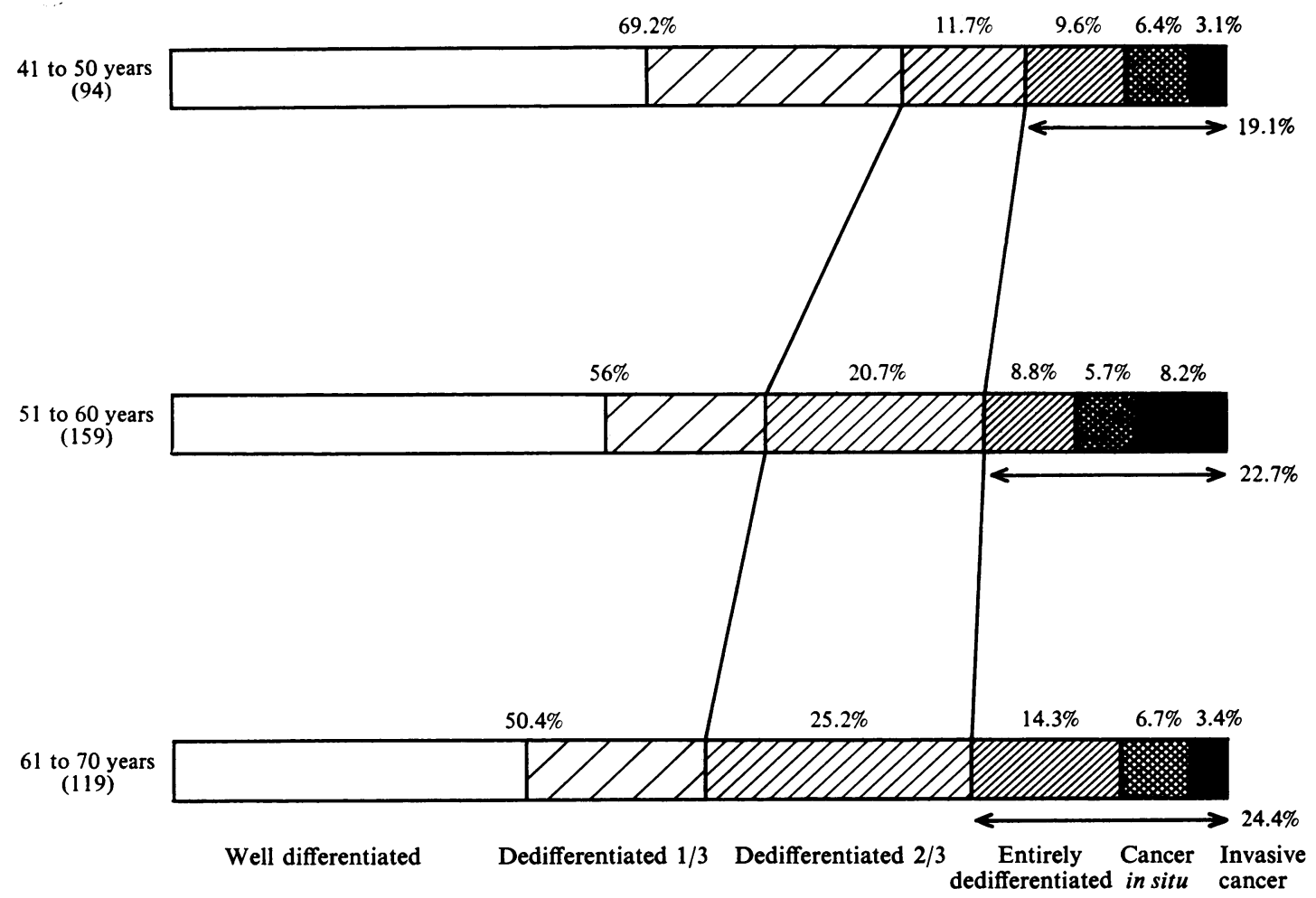

Fig. 14 Histology in relation to age: the three age groups that represent the occurrence of $80 \%$ of polyps, leaving out villous papillomas.

and 70 years. We have omitted villous papillomas from these statistics, because they are distinctive and because their constantly menacing character makes them different from true adenomas.

\section{HISTOLOGICAL TYPES IN THE TWO SEXES}

Table II shows that potentially malignant types are much more frequent in women. Especially important are the indeterminate types (complete dedifferentiation) and also villous polyadenomas.

If we recollect that cancers of the rectum and sigmoid colon are distributed nearly equally in the two sexes, it is interesting to note that polyps are fewer but more often malignant in women, the balance being thus reestablished.

\begin{tabular}{llll}
\hline & $\begin{array}{l}\text { Potentially } \\
\text { Malignant }\end{array}$ & $\begin{array}{l}\text { Malignant } \\
\text { Polyps }\end{array}$ & $\begin{array}{l}\text { Villous } \\
\text { Polyadenomas }\end{array}$ \\
\hline Men & $27 \cdot 7 \%$ & $11 \%$ & $5 \cdot 3 \%$ \\
Women & $41 \cdot 1 \%$ & $18 \%$ & $12 \%$ \\
\hline
\end{tabular}

Table II Histology in relation to sex
INCIDENCE AND HISTOLOGY OF MULTIPLE POLYPS

One quarter of patients with polyps have at least two of them, but the incidence of multiple polyps does not vary much with age: $22 \%$ at $30,28 \%$ at 70 years (Fig. 12). These figures conflict with other reports according to which the multiplicity of polyps does increase with age.

Multiplicity does not increase the risk of malignancy because $57 \%$ of multiple polyps are benign and $50 \%$ of solitary polyps are also benign. We include here small polyps, of Morson's metaplastic type, and it is possible that statistics which exclude this kind of growth could give different results.

\section{HISTOLOGY OF POLYPS ACCOMPANYING}

CARCINOMA

Our material is surgical and therefore selected. These results are the opposite of the ones given above. In 24 patients we found 31 polyps, of which 11 were malignant at least potentially.

The polyps accompanying cancer therefore have 


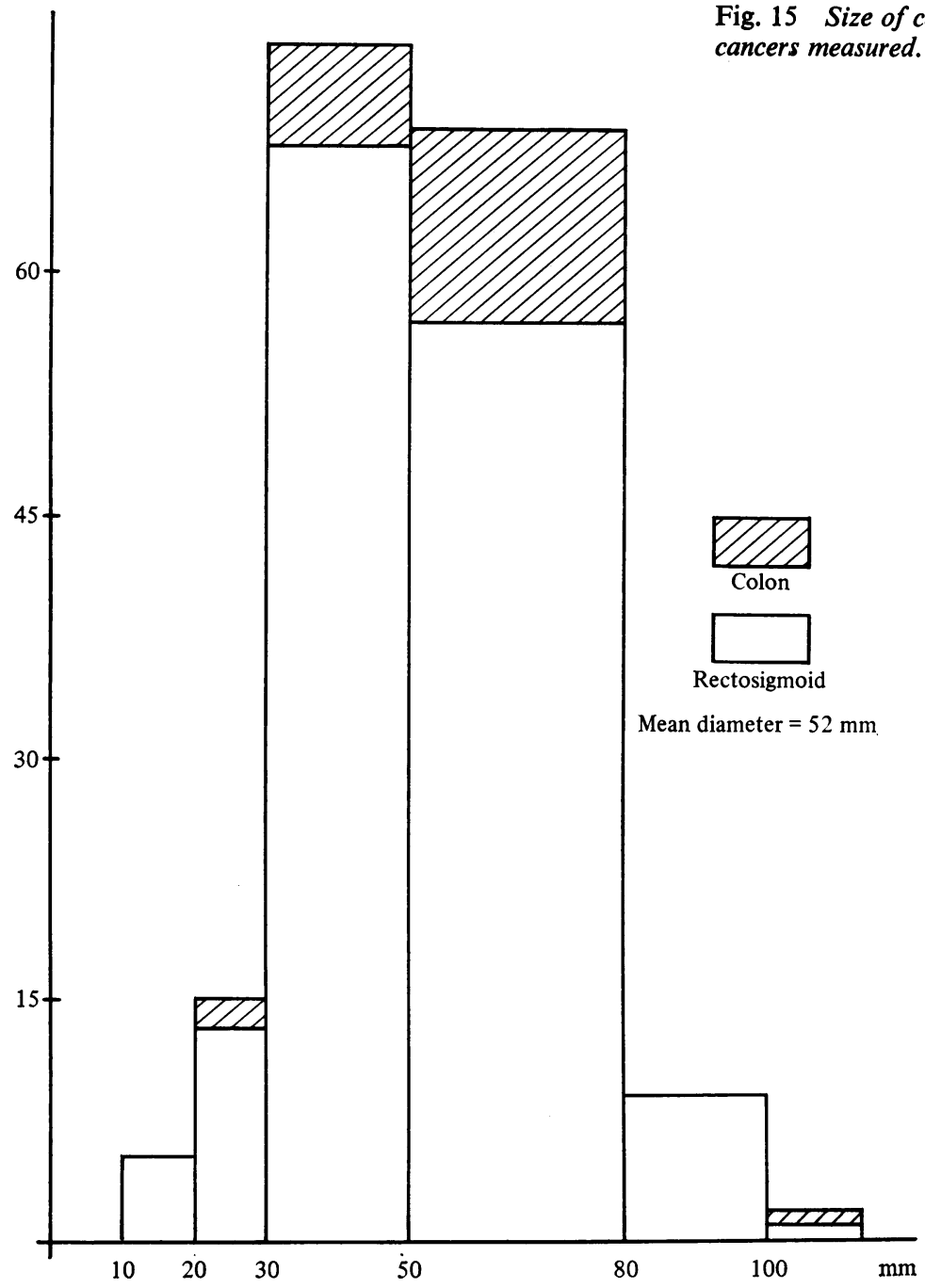

a menacing histology more frequently than the others and show a relatively consistent grouping. To those malignant polyps that accompany common cancers and those belonging to a particular variety of small cancers, it is interesting to compare our statistics for small cancers arising from a normal mucosa devoid of any polyp. (These data were collected in a gastroenterology department where proctoscopy is a routine examination performed in every patient with an anorectal condition.)

Out of 174 cancers diagnosed and operated on (Fig. 15) none were less than $10 \mathrm{~mm}$ in diameter, three measured less than $15 \mathrm{~mm}(10,12$, and $14 \mathrm{~mm}$ respectively). One of these already involved the submucosa extensively. Seven others were either less than or equal to $25 \mathrm{~mm}$ wide. These figures show that scarcely $6 \%$ of cancers of the rectum are relatively small, whereas almost half of them are more than $50 \mathrm{~mm}$ wide.

EVOLUTION AND RECURRENCE

Of 433 patients with polyps, 217 were followed up from between six months and 10 years. There were 47 recurrences $(22 \%)$.

NUMBER OF RECURRENCES OF DIFFERENT HISTOLOGICAL TYPES OF POLYP

Figure 16 shows that the histological appearance 

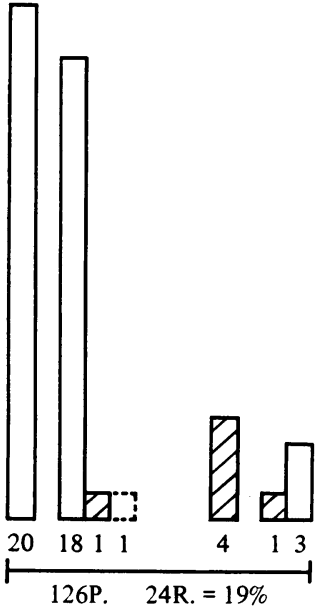

Well differentiated

Entirely dedifferentiated

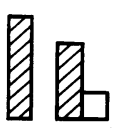

$4 \quad 31$
Fig. 16 Recurrence of polyps in relation to their histological types. does not change much in recurrent polyps and that recurrence is more frequent when the histology is unfavourable.

It must be pointed out that the follow-up examination was performed at irregular intervals, often a long time after recurrence of a polyp, which therefore was able to develop for a time before the histological verification, and this gives more weight to the stability observed. We have never seen a cancer develop in the place of a well differentiated benign polyp which has been surgically removed (Fig. 16).

\section{FUTURE OF UNRESECTED POLYPS}

Despite the scientific interest of such observations, the fact that polyps have not been resected is not usually the fault of the physician but rather of neglect by the patient. The observation is generally incomplete because either the information on initial histology or on the final evolution, when no resection has been performed, is lacking. In these cases, which are few enough to have no statistical value, the polyps were found, when resected after several years' evolution, to be well differentiated. They were initially so and thus have stayed.

We have not been able to follow the course of initially malignant polyps but such cases do exist. Although this is not the object of the present study, we can quote the case reports of de la Vaissiere,
Jourde, and Loygue (1965) concerning colonic cancers arising in polyps unrecognized on radiographs performed 15, eight; and seven years previously. Histological study of one of these cancers (first case) made it possible to find adenomatous remnants, thus giving proof of its origin. These polyps were therefore probably potentially malignant and developed over many years into true carcinoma. Their large initial size was an argument in favour of this idea, which is corroborated by the fact that they had long pedicles.

\section{Discussion}

The problem of polyps is important because of their relationship to cancer. But the histologist, who finally gives a diagnosis and a prognosis, depends very much on the physician. For it is he who interprets the symptoms, detects the polyps, decides on what material is to be given to the histologist, and finally handles the therapy.

\section{CLINICAL}

A proctoscopic examination must be performed on anyone with bleeding from the rectum, even if the amount is minimal or moderate, and when there are big haemorrhoids. Polyps and haemorrhoids often coexist, bleeding being due more often to the latter, but the polyp, though a less frequent cause of 
bleeding, should not be overlooked as a possible cause. But proctoscopy has limits, these varying with the individual anatomical disposition of the last part of the colon and also with the practitioner's skill. There is a risk of missing, by just a few centimetres, a polyp of the sigmoid colon, sometimes revealed by a few red or black bloody streaks of the mucosa of the upper part of the rectum. In such cases radiological examination of the sigmoid colon using contrast medium is a great help. If good preparation rids the intestine of faeces and gas so that the sigmoid colon can be visualized then a round filling defect and pedicle typical of a polyp can be seen. The size and surface appearance of such a polyp can then be estimated and the histological type be predicted.

Nevertheless only proctoscopy and biopsy allow immediate histological control. But such an examination is selective and the histologist may overestimate or underestimate the true situation; he can overestimate when a superficial fragment of polyp shows a dedifferentiation that only affects the surface region of the growth and can be caused by a secondary inflammatory process. More often the position is underestimated because patches of dedifferentiation or localized cytological abnormalities are missed. It is most important that information about the histology of the stalk should be obtained as this indicates whether local excision is practicable. Therefore many biopsies should be taken of the surface and at the base of the tumour.

Biopsy is most desirable when the macroscopic appearance is that of a tumour for which a local ablation under proctoscopic control would seem insufficient; biopsy avoids another proctoscopic examination. In the other cases it is best to do without biopsy, as Carden and Morson (1964) suggest, and to resect the tumour directly, usually by diathermy. In this way the histologist can examine and give an exact and complete description of the whole tumour. If this result shows that local ablation is not sufficient then a more extensive surgical resection will have to be performed.

\section{EVOLUTION OF MALIGNANCY}

Dedifferentiation seems to us to be the most satisfactory way to distinguish between benignancy and malignancy. Every tumour, however, should be cut and examined, and, as we have just said, the study of biopsy material by itself can be erroneous. Some dedifferentiations are widespread but incomplete and leave the histopathologist hesitant. Between benignancy and malignancy there is an uncertain zone, and modern and more precise techniques, impossible to use routinely, would make the study of this zone more efficient.

At the present time, this group of polyps, from

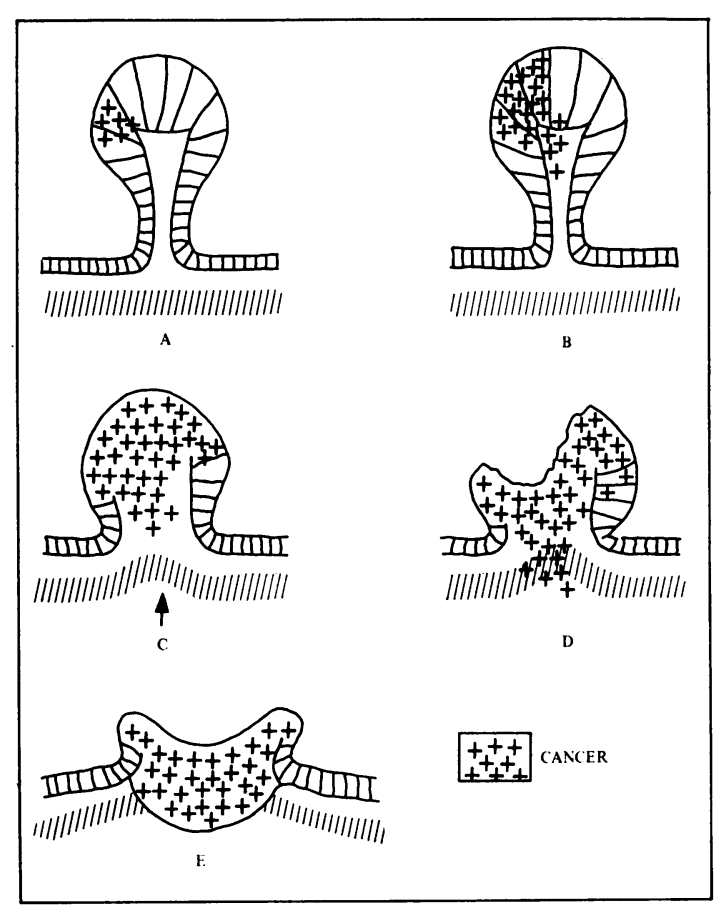

Fig. 17 Passage from a malignant polyp to a common cancer.

one-half to two-thirds dedifferentiated, still has an uncertain prognosis.

Benign polyps seem to be very stable. Otherwise their number would decrease considerably with age to the benefit of malignant polyps. The proportions of the two categories change little when the patient reaches the age of cancer, between $\mathbf{4 0}$ and $\mathbf{7 0}$ years. Those polyps appearing benign and not having undergone ablation were found to be unchanged when they were resected years later. Above all, study of recurrence after ablation has shown a structure identical to that of the original tumour. And we have never seen cancer at the site of a resected polyp.

Against this stability of benign polyps the evolution of those that first show at least a complete dedifferentiation, if not actual cytological characteristics of cancer in situ, must be matched. This evolution is probably difficult to observe because of its slow progress (Spratt, Ackerman, and Mayer, 1958; Spratt and Ackerman, 1961; Spratt, 1965). Can invasive cancer originate in malignant polyps? If this is the case, how can a lesion with a long pedicle change to an infiltrating and ulcerative one?

When the cancer breaks through the muscularis mucosae of the polyp it first reaches the axis and not the pedicle. At this stage the pedicle is still flexible 
and long: thus the presence of a long pedicle is not necessarily a reassuring sign. Later the pedicle is involved and this is usually preceded by desmoplasia that modifies the pedicle which grows wider and shorter. At the same time the rectal muscular wall is pulled towards the axis of the polyp. At this stage there are macroscopic signs of malignancy. The short pedicle is involved and loses its flexibility. The surface is often eroded. All this can be explained by the fact that the pedicle is a purely mechanical formation emanating from the rectal mucosa.

In some instances, a purely fungating cancer will result from this process. But, as in most cancers, an ischaemic process will often alter the structure, thus causing ulceration. We therefore propose the following scheme to explain the evolution from a malignant polyp to cancer (Fig. 17). (A) The malignant polyp at stage I has not spread beyond the muscularis mucosae. The pedicle is long and flexible. (B) The cancerous process breaks through the muscularis mucosae and reaches the axis of the polyp. This is stage II, but the pedicle is intact. (C) The polyp is completely involved by the cancerous growth but a few adenomatous remnants can still be found. The pedicle is involved and broadened. At this stage a macroscopic diagnosis of malignancy can be made.(D) Asymmetrical ulceration occurs : the cancer penetrates the muscular wall (stage III). If the figure is divided in two parts by a vertical line, the left side is already a cancer, the right side is still a malignant polyp.

Spratt et al (1958) discussed this method of evolution but rejected it because even if stages $\mathrm{A}, \mathrm{B}$, and $C$ could be found, stages $C$ and $D$ were exceptionally, if ever, encountered. We have looked for these stages in small cancers and have unquestionably found them. There is other evidence in favour of the idea that in most cases carcinoma originates in malignant polyps. The association of polyps with cancer is frequent and very small nonpolypoid cancers, which arise from an unaltered mucosa, are rare. Small cancers (less than $5 \mathrm{~mm}$ ) are only found in polyps. The evolution described above can also be observed in familial polyposis. Bockus et al (1961) compared the site of 129 benign polyps and 418 cancers of the rectum and found a remarkably similar distribution. Lastly, a few observers (Parturier-Albot and Miassarow, 1962; Morson, 1966; Warren cited by Swinton and Schatman, 1964; and de la Vaissiere et al, 1965) have followed this evolution of a pedunculated polyp into cancer in vivo.

\section{Therapeutic Indications}

The histological criteria for benignancy, potential malignancy, and actual malignancy are important because they indicate different treatments. Consequently, if local removal of benign polyps is the general practice, it is also evident that invasive cancer (stage II) should be treated surgically and widely resected, like any other cancer. What should be done about completely dedifferentiated polyps and about stage 0 or I cancers? Experience shows that this focal malignancy - as long as it stays focaldoes not show any risk of lymphatic invasion or of metastasis. Therefore these varieties can be treated like benign ones, by local removal, usually by diathermy. The base of the implantation must be carefully studied histologically, and it is prudent for the patient to be examined at least twice a year. Villous polyadenomas, that are more menacing and subject to early recurrence after ablation, require that the patient be examined quarterly during the first year. These examinations are useful for diagnosing not only a recurrence, but also new polyps in other sites. It is well known that polyps have a greater chance of recurring in patients who already have polyps than in patients who have never had any (Weakley and Swinton, 1962).

When adenomas inaccessible to proctoscopy have been diagnosed by a radiographic examination, then the only treatment is surgical through the abdomen. Two techniques can then be used: ablation of the polyps with resection of a collar of mucosa around the pedicle or resection of a segment of intestine. The first technique should be used for benign polyps or when there is focal malignancy. The second is necessary when malignancy is unquestionable. A frozen section should be taken for histological study of the tumour. If not, the surgeon has to base his decision on the appearance, and especially on the size, of the lesion, bearing in mind that large polyps have an increased propensity towards malignancy.

Even so the rest of the colon should be explored, for a radiographic examination, despite technical progress, can still be insufficient to detect multiple polyps. Palpation of the unopened colon is often misleading and opening it is not without danger. Colonic transillumination can help by inserting a thin cable made of glass fibres transmitting a beam of cold rays coming from an exterior source through the aperture made for extraction of the polyp. When the light intensity is well adjusted, the shadows of the polyps can be seen through the colonic wall. A recently developed fiberscope gives an excellent view.

\section{Conclusions}

The histological concept of dedifferentiation is essential for the understanding of polyps of the colon 
and rectum. The morphological and physiological changes that dedifferentiation signifies are a measure of the anarchy of their future development. When dedifferentiation involves the whole tumour, there is then no doubt about the potential malignancy. These signs are less evident than the nuclear anomalies or the disorderly growth patterns that make malignancy even more threatening. But this concept of a minimal malignancy is confirmed by studies of the evolution of polyps and by the absence of recurrence after treatment, which is more conservative than for more malignant tumours. As for the category of polyp between benign and malignant, which shows a great deal of proliferation but not complete dedifferentiation, no prognosis can yet be given. The prognosis, on the other hand, seems certain in very well differentiated tumours because statistics and studies of evolution confirm that they have a stable and benign behaviour.

Tumours which we call potentially malignant because they are completely dedifferentiated deserve to be so called, even when the cytological signs and growth pattern typical of actual cancer are absent, because all degrees of transition are possible from one stage to the other. The adenomatous remnants discovered in certain tumours indicate that the cancer had its origin in a polyp. A polyp does not suddenly become malignant because benign polyps do not acquire this potential; nevertheless even tiny polyps can be potentially malignant, and in familial polyposis we have seen malignancy precede the adenomatous proliferation. Proof that colonic adenomas can undergo malignant transformation has not been obtained. The benign polyp stays benign and the malignant polyp appears from its inception to have cancer potential.

Our statistics corroborate what we had already suggested after studying a smaller series (Potet, Soullard, and Lambling, 1962). It seems that the cards are dealt at the start of the game and that the destiny of these adenomas is written down in their first cells.

\section{References}

Ackermann, L. V., Spjut, H. J., and Spratt, J. S. (1964). The biological characteristics of colonic and rectal neoplasms with refutation of the concept that adenomatous polyps are highly premalignant tumors. Acta. Un. int. Cancr., 20, 716-723.

Arminski, T.C., and McLean, R.W.(1964). Incidence and distribution of adenomatous polyps of the colon and rectum based on 1,000 autopsy examination. Dis. Col. Rect., 7, 249-261.

Bargen, J. A., cited by Castro, A. F. (1963). A reappraisal of the colonic polyps. Med. Ann. D.C., 32, 11-17 and 38.

Bockus, H. L., Tachdjian, V., Ferguson, L. K., Mouhran, Y., and Chamberlain, C. (1961). Adenomatous polyp of colon and rectum; its relation to carcinoma. Gastroenterology, 41, 225-232.
Carden, A. B. G., and Morson, B. C. (1964). Recurrence after local excision of malignant polyps of the rectum. Proc. roy. Soc. Med., 57, 559-561.

Castleman, B., and Krickstein, H. I. (1962). Do adenomatous polyps of the colon become malignant? New Engl. J. Med., 267, 469-475.

Chapman, I. (1963). Adenomatous polypi of large intestine: incidence and distribution. Ann. Surg., 157, 223-226.

Ekelund, G. (1963). On cancer and polyps of colon and rectum. Acta path. microbiol. Scand., 59, 165-170.

Enterline, H. T., Evans, G. W., Mercado-Lugo, R., Miller, L., and Fitts, W. T., Jr. (1962). Malignant potential of adenomas of colon and rectum. J. Amer. med. Ass., 179, 322-330.

Feyrter, F. (1931). Zur Geschwulstlehre (nach Untersuchungen am menschlichen Darm): Polypen and Krebs. Beitr. path. Anat., 86, 663-760.

Fitts, W. T.. Jr., (1961). Adenomas of the colon and rectum: their malignant potential. Amer. J. Surg., 101, 87-90.

Grinnell, R. S. (1964). The chance of cancer and lymphatic metastasis in small colon tumors discovered on X-rays examination. Ann. Surg., 159, 132-138.

Helwig, F. C. (1960). The association of benign and malign polyps of the large intestine. Dis. Colon Rect., 3, 343-346.

Knight, I. A. (1963). Colon and rectal polyps, relationship in carcinoma. California Med., 99, 378-381.

Lescher, Th., C., Dockerty, M. B., Jackman, R. J., and Beahrs, O. H. (1967). Histopathology of the larger colonic polyp. Dis. Colon Rect. 10, 118-124.

de la Vaissiere, G., Jourde, L., and Loygue, J. (1965). Adénomes solitaires du colon gauche dégénérés ou polypes malins? Ann. Chir., 19, 206-213.

Martin, J. D., Jr., and Sutton, G. (1965). Present status of polyps of the colon: classification and malignant potential. Amer. Surg., $31,551-558$.

Mayo, C. W., and Pagtalunan, R. J. G. (1963). Malignancy of colon and rectum in patients under 30 years of age. Surgery, 53, 711718.

Morson, B. C. (1962). Precancerous lesions of the colon and rectum: classification and controversial issues. J. Amer. med. Ass., 179, 316-321.

Morson, B. C. (1966). Factors influencing the prognosis of early cancer of the rectum. Proc. roy. Soc. Med., 59, 607-608.

Morson, B. C., and Bussey, H. J. R. (1970). Predisposing causes of intestinal cancer. Curr. Probl. Surg. Feb., 1-46.

Parturier-Albot, M.,' and Miansarow, H. (1962). Les aspects endoscopiques périlésionnels des formes de début du cancer du rectum. Sem. Hôp. Paris., 38, 1666-1677.

Potet, F., Soullard, J., and Lambling, A. (1962). Polypes et cancer du recto-sigmoide. Étude critique de la dégénérescence et hypothèse de filiation. Presse Méd., 70, 865-868.

Rider, J. A., Kirsner, J. B., Moeller, J. C., and Palmer, W. L. (1959). Polyps of the colon and rectum: a four-year to nine-year followup study of five hundred thirty-seven patients. J. Amer. med. Ass., 170, 633-638.

Spratt, J. S., Jr., and Ackerman, L. V. (1961). The growth of a colonic adenocarcinoma. Amer. Surg., 27, 23-28.

Spratt, J. S., Jr. (1965). The rates and pattern of growth of neoplasms of the large intestine and rectum. Surg. Clin. N. Amer., 45, 1103-1115.

Spratt, J. S., Jr., Ackerman, L. V., and Moyer, C. A. (1958). Relationship of polyps of colon to colonic cancer. Ann. Surg., 148, 682698.

Stearns, M. W. Jr., (1963). Where are the tiny carcinomas of the rectum? Surg. Gynec. Obstet., 116, 625.

Swinton, N. W., and Schatman, B. H. (1964). Present-day concepts of rectal and colon polyps and their relation to cancer. $J$. Lancet, 84, 111-113.

Warren, S. (1964). Personal communication.

Weakley, F. L., and Swinton, N. W. (1962). Follow-up study of patients with benign mucosal polyps of the rectum. Dis. Colon Rect., 5, 345-348.

Wechselmann, L. (1910). Polyp and Carcinom in Magen-Darmkanal. Bruns' Beitr. hlin. Chir., 70, 855-904.

Welch, C. E., McKittrick, J. B., and Behringer, G. (1952). Polyps of the rectum and the colon and their relation to cancer. New Engl. J. Med., 247, 959-965. 